\title{
Krill population dynamics at South Georgia 1991-1997, based on data from predators and nets
}

\author{
Keith Reid*, Jon L. Watkins, John P. Croxall, Eugene J. Murphy \\ British Antarctic Survey, Natural Environment Research Council, High Cross, Madingley Road, Cambridge CB3 OET, UK
}

\begin{abstract}
Central to understanding krill population dynamics is knowledge of their population structure. To examine this we used length-frequency distributions from $142 \mathrm{wk}$ of sampling ( $\mathrm{n}=23996$ krill) of 3 predator species breeding at South Georgia and $12 \mathrm{wk}$ of sampling ( $\mathrm{n}=10252 \mathrm{krill}$ ) from scientific nets from the same area over the summers of 1991-1997. In comparing the 5 years for which both predator and net samples were available, despite differing selectivities and spatio-temporal circumscriptions, both predators and nets were sampling the same overall krill population. Greatest similarity resulted from comparing net samples with samples from Antarctic fur seals and macaroni penguins combined; least temporal variation occurred in predator samples from late summer (March). From the 7 yr predator time series, within-year variation was greatest in 1991 and 1994, both years of low krill biomass at South Georgia. In both of these years large krill dominated during December but were completely replaced by small krill by February. The mean length of the March krill population showed a regular increase from 1991 to 1993, fell to a minimum in 1994 and thereafter increased steadily to 1997 Using these data in conjunction with putative size/age-group cohorts in the lengthfrequency distribution, we suggest that years of high mean krill length reflect failure of small krill to recruit into the population, producing a period of low krill biomass in the following year. Similar recruitment failure in the same years was evident in krill populations in the Antarctic Peninsula region to the south, indicating large-scale events. This supports suggestions of periodic fluctuations in krill production and recruitment which may relate directly to physical phenomena such as cycles in the distribution and extent of sea ice.
\end{abstract}

KEY WORDS: Krill · South Georgia - Antarctic fur seal · Macaroni penguin - Gentoo penguin · RMT 8

\section{INTRODUCTION}

The central role of Antarctic krill Euphausia superba in the Southern Ocean food web has made it the focus of extensive research (for example Marr 1962, Everson 1976, Miller \& Hampton 1989). This research has identified South Georgia as an area of generally high krill biomass; however, it has also indicated considerable interannual variability, with an almost complete absence of krill in some years (Priddle et al. 1988, Brierley et al. 1997). Large numbers of marine predators, especially seabirds and seals, breed at South Georgia, and krill is the single most important prey species for many of them (Kock et al. 1994, Croxall et al. 1997). Since

•E-mail:k.reid@bas.ac.uk there are clear links between the amount of krill in the diet of predators and their reproductive performance (Croxall et al. 1988, Boyd et al. 1994), knowledge of the mechanisms underlying changes in the krill population is crucial to understanding the population dynamics of these higher predator species (Murphy 1995). Understanding of the dynamics of the krill population requires knowledge of its population structure, recruitment and mortality processes as well as the physical movement of krill into and around the area of interest. Of these elements, the population structure is fundamental because it can provide information on absolute and relative recruitment and also be used to infer mortality and/or transport rates.

There are 2 principal sources of material for assessing the population structure of krill: scientific net samples and predator diet samples. The extent to which 
these 2 sampling techniques reflect the local krill population has been assessed for single species in different years (Croxall \& Pilcher 1984), single species in the same year (Hill et al. 1996) and for a range of species in the same year (Reid et al. 1996). These detailed analyses identified consistent biases towards large (in particular female) krill in predator samples compared to nets. However, the krill taken by predators and nets in 1981 and 1983 respectively (Croxall \& Pilcher 1984) showed much lower congruence than did samples from both sources collected in 1986 (Reid et al. 1996). Such differences in the level of congruence between net and predator samples and in the characteristics of krill between years in the diet of marine predators (e.g Antarctic fur seal; Reid \& Arnould 1996) indicate the potential limitations of short-term studies.

The length-frequency distributions of krill from both predators and nets usually represent the combination of data from a number of samples. Within these composite distributions there is potential for a number of biases resulting from differences in the temporal and geographical provenance of the samples. Net composites can allow for biases resulting from known differences in geographical origin of samples by careful design, whereas predator samples are typically of unknown geographical origin (though within the foraging footprint of the species involved, which is often known to within $\pm 50 \mathrm{~km}$ ). Within a particular year or season predator samples can usually be collected over a longer time-span than net samples, the former typically providing a better time series than the latter. In addition biases may arise simply as a function of the differing selectivities of nets, which may be biased against large krill (Everson \& Bone 1986. Hovekamp 1989), and predators, which may be biased in favour of large krill (Hill et al. 1996, Reid et al. 1996). Thus in comparing krill from these 2 sources it may be essential to distinguish the spatio-temporal bias from the selectivity bias.

This paper examines length-frequency distributions of krill taken by 3 species of marine predators and scientific net hauls at South Georgia during the period 1991-1997 in order (1) to determine to what extent krill in the diet of marine predators reflects the krill population characteristics shown by scientific net haul samples, and (2) to use the extended time series of predator data to investigate the patterns of variability in the krill population over this 7 yr period.

\section{METHODS}

Sample collection. Krill samples from predators (gentoo penguin Pygoscelis papua, macaroni penguin Eudyptes chrysolophus and Antarctic fur seal Arcto- cephalus gazella) were collected at Bird Island, South Georgia, during the austral summers of 1991-1997 the austral summer is given as the second part of the split year, i.e. $1990 / 1=1991$ ). Samples from gentoo and macaroni penguins were collected by stomach lavage of adult birds returning to feed chicks during February (see Croxall et al. 1997); data from Antarctic fur seals come from scat samples collected during the lactation period (December to March), following the method of Reid \& Arnould (1996) .

Net-caught krill samples include only those taken using an RMT 8 around South Georgia during the period December to February in 1991, 1993, 1994, 1996 and 1997.

Krill measurement. All krill length measurements are given as the total length (AT); for net-caught krill these were measured directly from the front of the eye to the tip of the telson (Lockyer 1973), whereas those from predators were estimated from the removed carapace length (RCL), using the appropriate regression models in Hill (1990).

Length-frequency distributions are presented at 2 $\mathrm{mm}$ length classes between 20 and $70 \mathrm{~mm}$ AT. All composite length-frequency distributions were calculated by summing proportions across size classes to normalise the samples with respect to sample size. The Shannon-Weaver index of diversity (Shannon \& Weaver 1949) was used as a measure of how evenly the individuals of a sample are apportioned between 2 mm length classes and is defined as:

$$
H=-\sum p_{i} \ln p_{i}
$$

where $p_{1}$ is the proportion of krill in each $2 \mathrm{~mm}$ size class. An overlap index $(C)$ was used to measure the degree of overlap in the length-frequency distribution between species and was calculated following Croxall et al. (1997) as:

$$
C=\frac{2 \sum_{i=1}^{s} x_{i} y_{i}}{\sum_{i=1}^{s} x_{i}^{2}+\sum_{i=1}^{s} y_{i}^{2}}
$$

where $s$ is the number of krill length classes in the diets of species $x$ and $y$.

\section{RESULTS}

A total of 34248 krill was measured during the period 1991-1997, 23996 from predators and 10252 from scientific nets (Table 1 ). The first part of this section deals with the magnitude and nature of the differences between these 2 data sets. Taking account of these, the second part uses the predator time series to examine krill population processes. 
Table 1. Timing of sampling and sample sizes of krill collected from Antarctic fur seal, gentoo penguin, macaroni penguin and research cruise nets at South Georgia from 1991-1997

\begin{tabular}{|c|c|c|c|c|c|c|c|c|}
\hline Source & 1991 & 1992 & 1993 & 1994 & 1995 & 1996 & 1997 & Total \\
\hline \multicolumn{9}{|c|}{ Antarctic fur seal } \\
\hline $\mathrm{n}$ & 1479 & 820 & 1582 & 1503 & 1193 & 1565 & 1439 & 9581 \\
\hline Begin & 28 Dec 1990 & $03 \operatorname{Jan} 1992$ & 18 Dec 1992 & 28 Dec 1993 & 11 Dec 1994 & 18 Dec 1995 & 21 Dec 1996 & \\
\hline End & 23 Mar 1991 & $26 \operatorname{Mar} 1992$ & 20 Mar 1993 & 06 Apr 1994 & 20 Mar 1995 & 18 Mar 1996 & 23 Mar 1997 & \\
\hline \multicolumn{9}{|c|}{ Gentoo penguin } \\
\hline $\mathrm{n}$ & 78 & 1155 & 1390 & 35 & 1460 & 887 & 1.155 & 6160 \\
\hline Begin & 28 Jan 1991 & $17 \operatorname{Jan} 1992$ & 21 Dec 1992 & $17 \operatorname{Jan} 1.994$ & 18 Jan 1995 & 12 Jan 1996 & $16 \operatorname{Jan} 1997$ & \\
\hline End & 19 Feb 1991 & 06 Feb 1992 & $11 \mathrm{Jan} 1993$ & 07 Feb 1994 & 09 Feb 1995 & 02 Feb 1996 & 04 Feb 1997 & \\
\hline \multicolumn{9}{|c|}{ Macaroni penguin } \\
\hline $\mathrm{n}$ & 153 & 820 & 1582 & 1503 & 1193 & 1565 & 1439 & 8255 \\
\hline Begin & 29 Jan 1991 & 23 Jan 1992 & $25 \operatorname{Jan} 1993$ & $25 \operatorname{Jan} 1995$ & $23 \operatorname{Jan} 1995$ & $17 \operatorname{Jan} 1996$ & $21 \operatorname{Jan} 1997$ & \\
\hline End & 19 Feb 1991 & 13 Feb 1992 & 16 Feb 1993 & 14 Feb 1994 & 14 Feb 1995 & 11 Feb 1996 & 12 Feb 1997 & \\
\hline \multicolumn{9}{|c|}{ Scientific cruise } \\
\hline $\mathrm{n}$ & 2013 & & 1769 & 600 & & 4252 & 1618 & 10252 \\
\hline Begin & $12 \operatorname{Jan} 1991$ & & $05 \mathrm{Jan} 1993$ & $01 \mathrm{Jan} 1994$ & & $03 \operatorname{Jan} 1996$ & 23 Dec 1996 & \\
\hline End & 15 Feb 1991 & & $26 \operatorname{Jan} 1993$ & 28 Feb 1994 & & $27 \operatorname{Jan} 1996$ & 03 Jan 1997 & \\
\hline Cruise ID & JB11 & & JR03 & JR06 & & JR11 & JR17 & \\
\hline Total & 3723 & 2795 & 6323 & 3641 & 3846 & 8269 & 5651 & 34248 \\
\hline
\end{tabular}

\section{Krill from predators and nets: similarities and differences}

There were differences in the krill taken by predators in each year. These broadly reflected the differences in krill from nets (Fig. 1). In 1991 the length-frequency distribution from both nets and predators was relatively limited in range about a single mode around 40 to $44 \mathrm{~mm}$. In 1993 the situation was similar, with a mode around 44 to $46 \mathrm{~mm}$ in both distributions. Both length-frequency distributions from 1994 were clearly bi-modal, with similar modes at 38 to $42 \mathrm{~mm}$ and 54 to $58 \mathrm{~mm}$. In 1996 the differences were more marked, with krill from predators mainly showing a mode at $42 \mathrm{~mm}$ (with a much smaller proportion forming a less well marked mode around $28 \mathrm{~mm}$ ); conversely net haul krill were mainly around the mode at $28 \mathrm{~mm}$, with a much smaller proportion around $42 \mathrm{~mm}$. Predator samples from 1997, which were very similar to those from 1993, had a single mode at $44 \mathrm{~mm}$, whereas the net samples had modes at both 38 and $48 \mathrm{~mm}$. Thus in most years the dominant modes coincided; in those years when this was not the case the same modes were at least represented in the complementary sample. Despite this overall similarity of krill length-frequency distributions from predators and nets, there were significant fine-scale differences between the lengthfrequency distributions in each year (Table 2). However, these differences need careful consideration before ascribing any biological significance to them.

In 1991 and 1993 both predator and net samples were composed primarily of the same unimodal length-frequency distributions, with a slight bias towards larger krill in the predators (Fig. 1). However, when all samples from 1993 were examined in detail, there was a suggestion that large krill became more apparent in the diet of predators during the course of the season (Fig. 2). This suggests that the overall bias towards larger krill in predator samples may simply reflect the different temporal scales over which the samples were collected.

In 1994 there were very substantial changes in the krill taken by predators through the course of the season (Fig. 3). The overall bimodality in the predator samples reflects the change from unimodal samples of

Table 2. Difference between predator and net length-frequency distributions, $D_{\max }$ is the maximum difference and $D_{\text {mean }}$ the mean difference between equivalent length categories from comparison of cumulative length-frequency distribution from a series of Kolmogorov-Smirnov 2-sample tests. All $D_{\mathrm{n} \text { ax }}$ values are significant at $\mathrm{p}<0.05$ using critical values from the Kolmogorov-Smirnov test

\begin{tabular}{|ccccc|}
\hline Year & $\begin{array}{c}\text { All } \\
\text { predators }\end{array}$ & $\begin{array}{c}\text { Antarctic } \\
\text { fur seal }\end{array}$ & $\begin{array}{c}\text { Gentoo } \\
\text { penguin }\end{array}$ & $\begin{array}{c}\text { Macaroni } \\
\text { penguin }\end{array}$ \\
\hline $1991 D_{\text {max }}$ & 0.325 & 0.375 & 0.449 & 0.184 \\
$D_{\text {mean }}$ & 0.065 & 0.083 & 0.079 & 0.035 \\
$1993 D_{\text {max }}$ & 0.338 & 0.297 & 0.334 & 0.396 \\
$D_{\text {mean }}$ & 0.080 & 0.084 & 0.065 & 0.092 \\
$1994 D_{\text {max }}$ & 0.333 & 0.161 & 0.421 & 0.415 \\
$D_{\text {mean }}$ & 0.069 & 0.040 & 0.085 & 0.095 \\
$1996 D_{\text {max }}$ & 0.479 & 0.672 & 0.595 & 0.216 \\
$D_{\text {mean }}$ & 0.128 & 0.195 & 0.163 & 0.057 \\
$1997 D_{\text {max }}$ & 0.296 & 0.481 & 0.444 & 0.228 \\
$D_{\text {mean }}$ & 0.084 & 0.145 & 0.125 & 0.057 \\
\hline
\end{tabular}




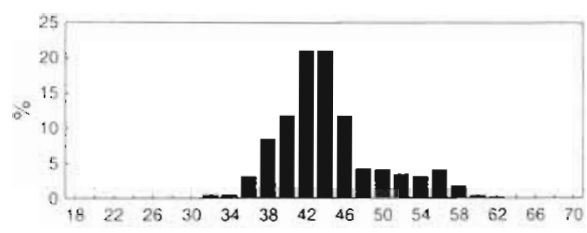

1991

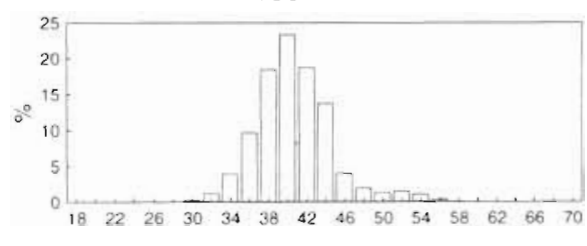

1991

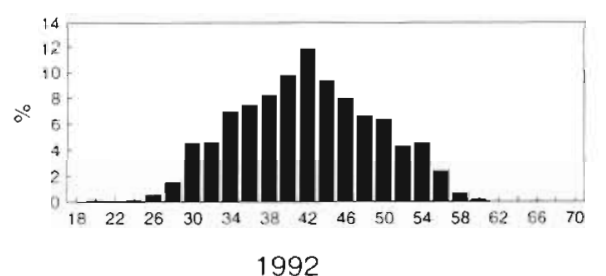

1992
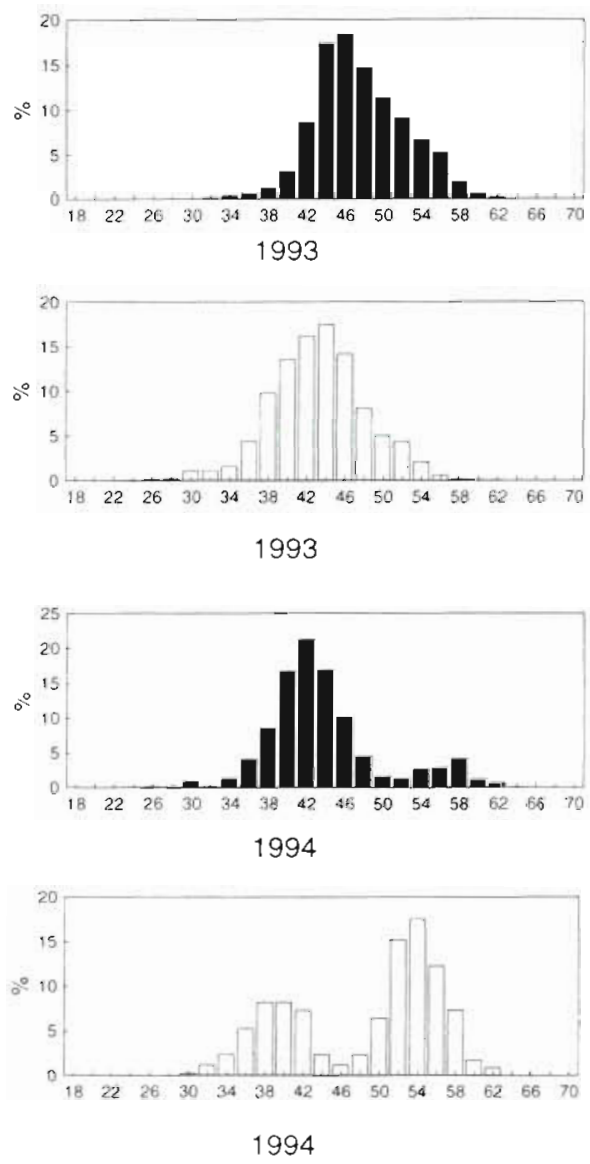

Krill Length (mm)
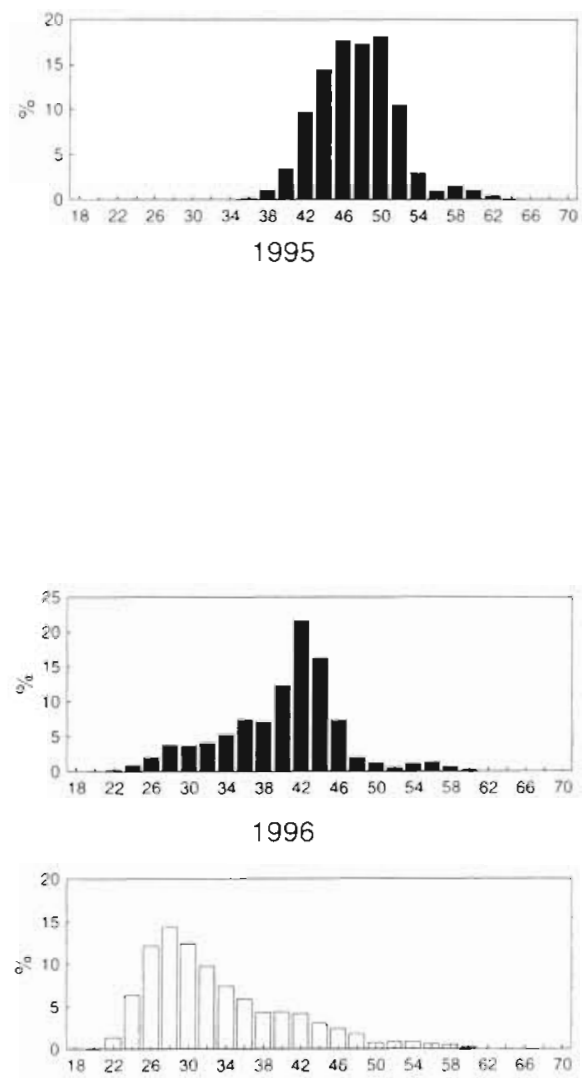

1996
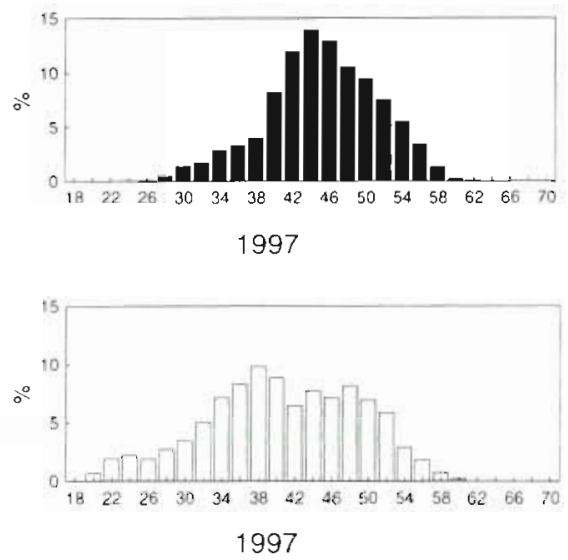

Fig. 1. Length-frequency distribution of krill taken each year by predators ( $\square$ ) and nets (D) during the period 19911997 


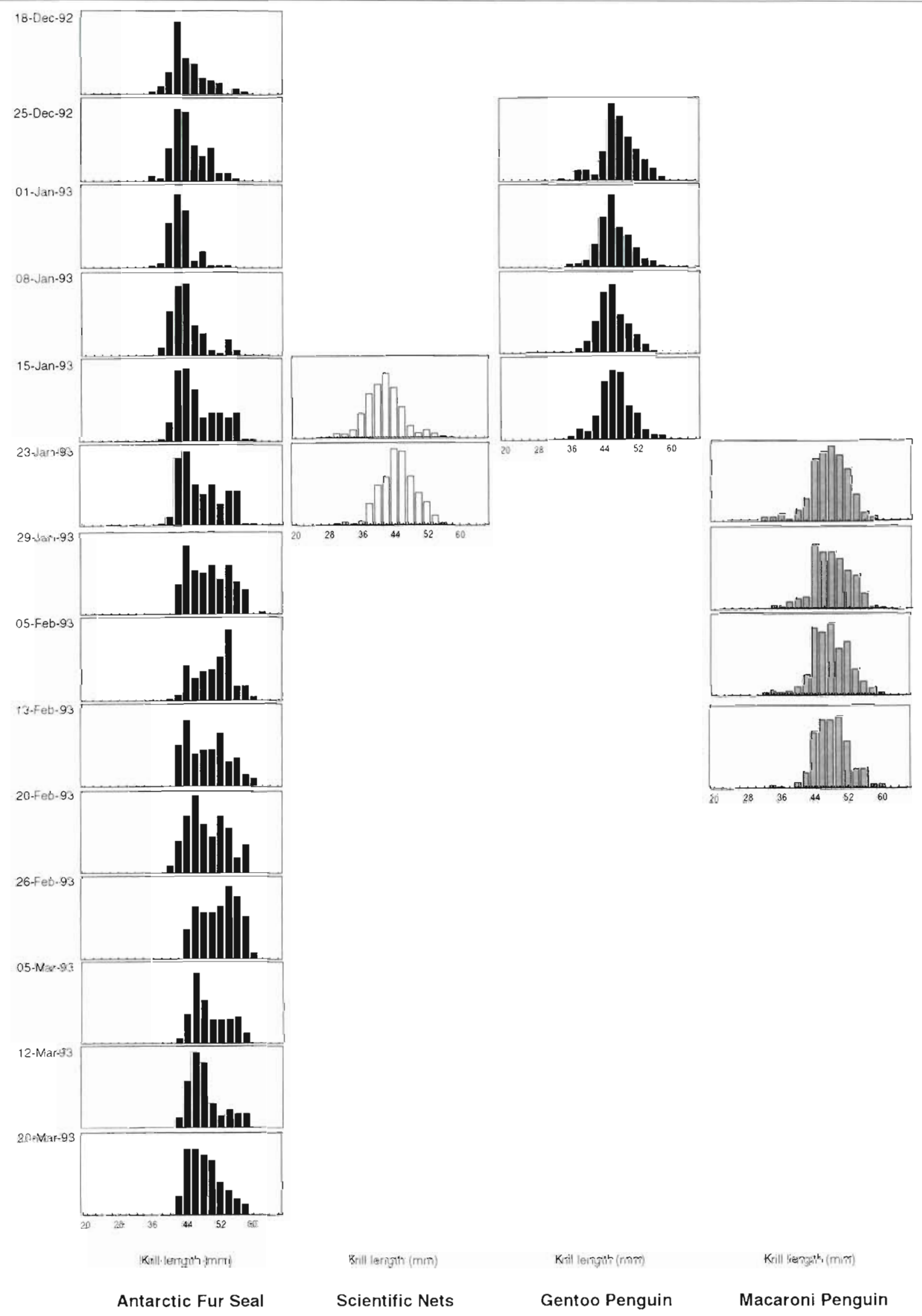

Fig. 2. Sequence of krill length-frequency distribution from Antarctic fur seals, scientific nets, gentoo penguins and macaroni penguins during the period December 1992 to March 1993 


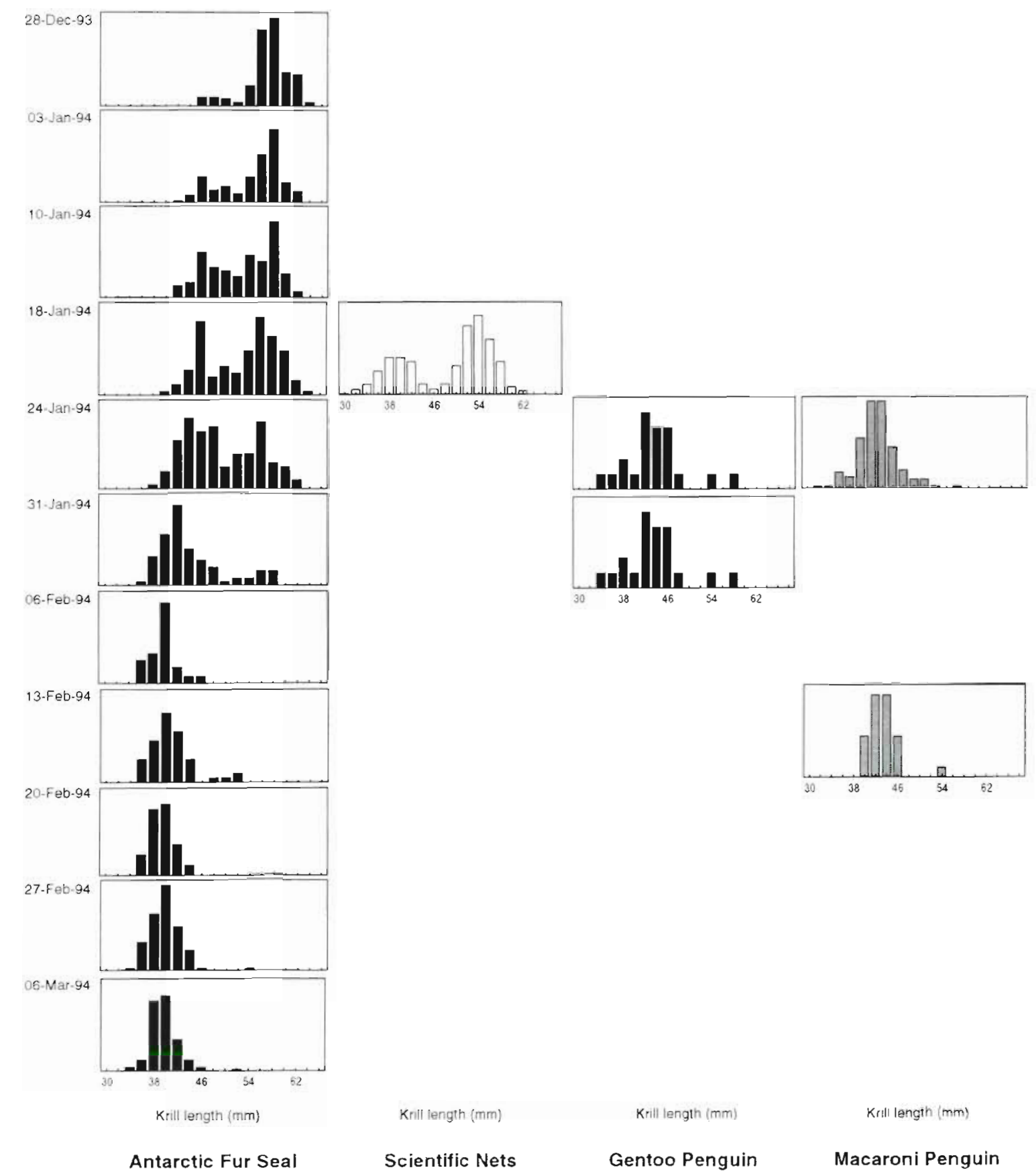

Fig. 3. Sequence of krill length-frequency distribution from Antarctic fur seals, scientific nets, gentoo penguins and macaroni penguins during the period December 1993 to March 1994

large krill early in the season to unimodal samples of small krill later on. The timing of the net samples coincides with the period when both modes were represented in the samples from Antarctic fur seals. Therefore, while net and predator samples showed similar modal sizes, the differences in the relative magnitude of these modes may result from sampling over different time-spans
In 1996, unlike 1994, there was no indication of a temporal change in the krill taken by predators; however, this year showed the greatest difference between net and predator samples (Fig. 4). The net samples combine krill of different geographical origin, with 2 samples from the east and a third sample from the northwest end of South Georgia (Watkins et al. unpubl,j. By restricting the comparison with predator 


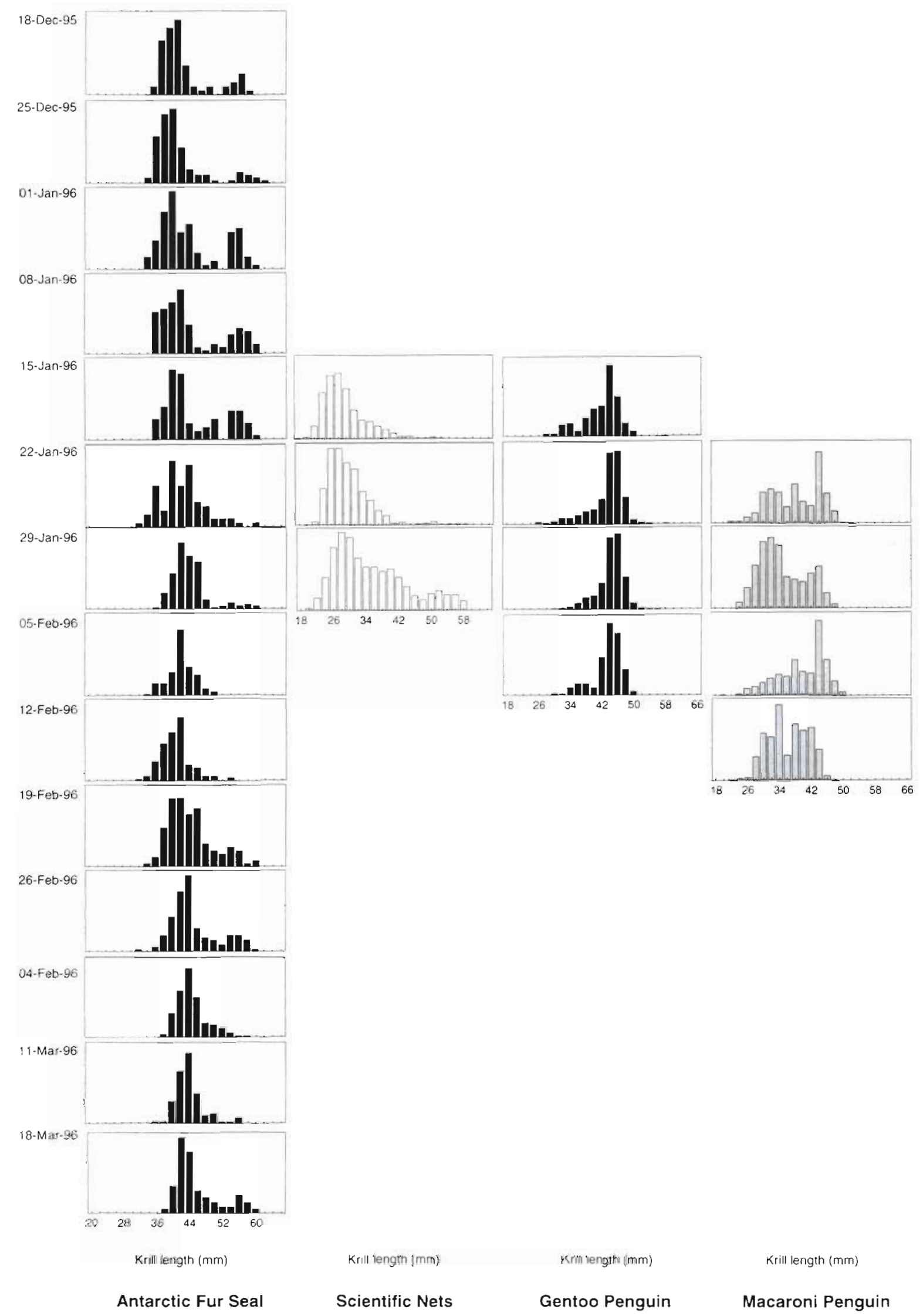

Fig. 4. Sequence of krill length-frequency distribution from Antarctic fur seals, scientific nets, gentoo penguins and macaroni penguins during the period December 1995 to March 1996. 
samples to those net samples taken close to Bird Island, the mean difference between predator and nets was reduced to 0.09 , compared to 0.13 for the overall comparison. A similar situation occurred in 1997, when the bimodality in overall net samples resulted from the geographical differences between the 2 wk of net sampling (Watkins et al. unpubl. data); the difference between the overall predator length-frequency distribution was reduced from 0.08 to 0.06 when comparison was restricted to net samples from the northwest end of South Georgia. From this detailed examination it is clear that krill in the diet of predators reflects the major components of the krill population very well. There are normally small differences resulting from differences in the temporal and spatial distribution of sampling and because the predator samples typically show some under-representation of the smallest size class of krill compared to net samples.

\section{Differences between predators}

In the previous section the overall predator lengthfrequency distributions (Fig. 1) were derived from combined data from Antarctic fur seals, macaroni penguins and gentoo penguins. When these species were considered separately there was a significant relationship between the Shannon-Weaver index of diversity in net samples and the mean level of overlap in the length-frequency distributions of krill taken by macaroni penguins and Antarctic fur seals $(r=-0.88, p<$ 0.05 ) (Fig. 5), such that, with a more heterogeneous krill population in the net samples, there was a reduced level of overlap between these 2 predators. This was not the case for gentoo penguins and Antarctic fur seals $(r=0.16, n s)$ or gentoo penguins and macaroni penguins $(\mathrm{r}=-0.11, \mathrm{~ns})$. The principal difference

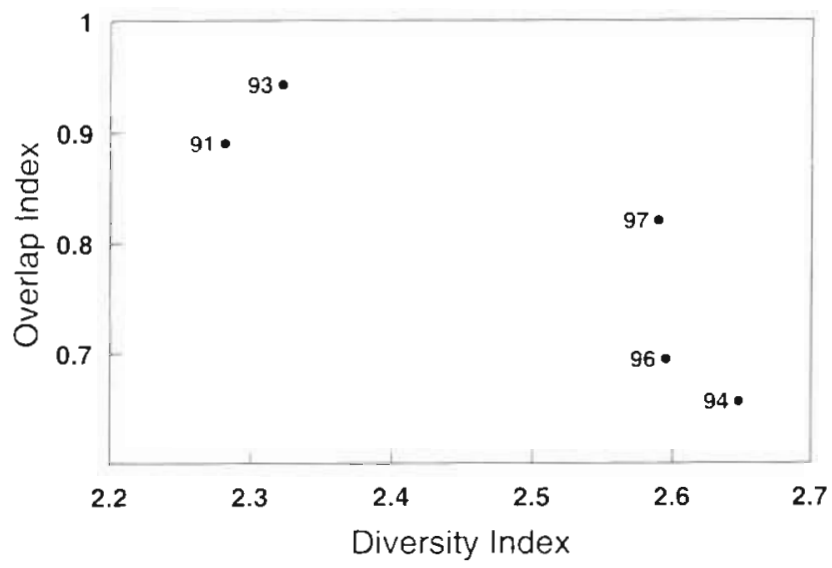

Fig. 5. Relationship between diversity of krill in nets and the overlap indices between the krill diet of Antarctic fur seals, macaroni and gentoo penguin between the krill taken by macaroni penguins and Antarctic fur seals was that, while the former took krill of less than $36 \mathrm{~mm}$, krill of this size were not generally present in samples from Antarctic fur seals. This was particularly apparent in 1996 when krill of less than $36 \mathrm{~mm}$ dominated net samples, were absent from the diet of Antarctic fur seals but were the dominant size class in macaroni penguin samples (Fig. 4). Thus combining data from Antarctic fur seals and macaroni penguins covers a comparable size range of krill to that from nets and ensures that the same modes are represented, albeit with different relative magnitudes.

\section{Krill population processes}

Combining data from Antarctic fur seals and macaroni penguins, thereby covering the fuil size range of the krill population, is only possible with current data for 4 wk each year. For examination of krill population processes, therefore, the extended time series of data (12 to $14 \mathrm{wk}$ ) makes the Antarctic fur seal the more suitable species. While these samples are likely to under represent small krill, this bias is unlikely to be a problem for the inter-annual comparisons that are the main objective here.

The variation in the mean length of krill taken by Antarctic fur seals during the summers of 1991-1997 indicates substantial intra- and inter-annual variability (Fig 6). To facilitate comparisons between years we calculated (1) the overall change in mean krill length between the first and last 3 wk for which samples were consistently available (weeks ending 28 December to 10 January and 8 to 23 March), and (2) the average change in mean length between weeks (Table 3 ).

In 1991 and especially 1994 the greatest intra-annual differences occurred, both years being characterised by considerable reductions in the size of krill taken between January and March. In 1994 this change

Table 3. Descriptors of the krill taken by Antarctic fur seals from 1991-1997. Mean length of krill during period 28 December to 10 January (Early) and 8 to 23 March (Late) and the differences between these (Change) are given along with the mean and variance for the difference between mean krill length in consecutive weeks

\begin{tabular}{|rrrrrc|}
\hline Year & Early & Late & Change & Mean & Variance \\
\hline 1991 & 52.0 & 41.7 & -10.30 & 2.29 & 4.37 \\
1992 & 44.8 & 45.2 & 0.37 & 2.09 & 0.91 \\
1993 & 43.1 & 47.7 & 4.57 & 1.37 & 0.84 \\
1994 & 54.7 & 39.0 & -15.70 & 1.78 & 2.98 \\
1995 & 44.1 & 42.2 & -1.86 & 0.85 & 0.30 \\
1996 & 41.5 & 44.0 & 2.47 & 1.41 & 1.17 \\
1997 & 48.6 & 47.6 & -1.00 & 1.34 & 1.04 \\
\hline
\end{tabular}


Fig. 6. Weekly variation in mean krill length in the diet of Antarctic fur seal during the breeding seasons of 1991 1997 (error bars show \pm 1 SE)

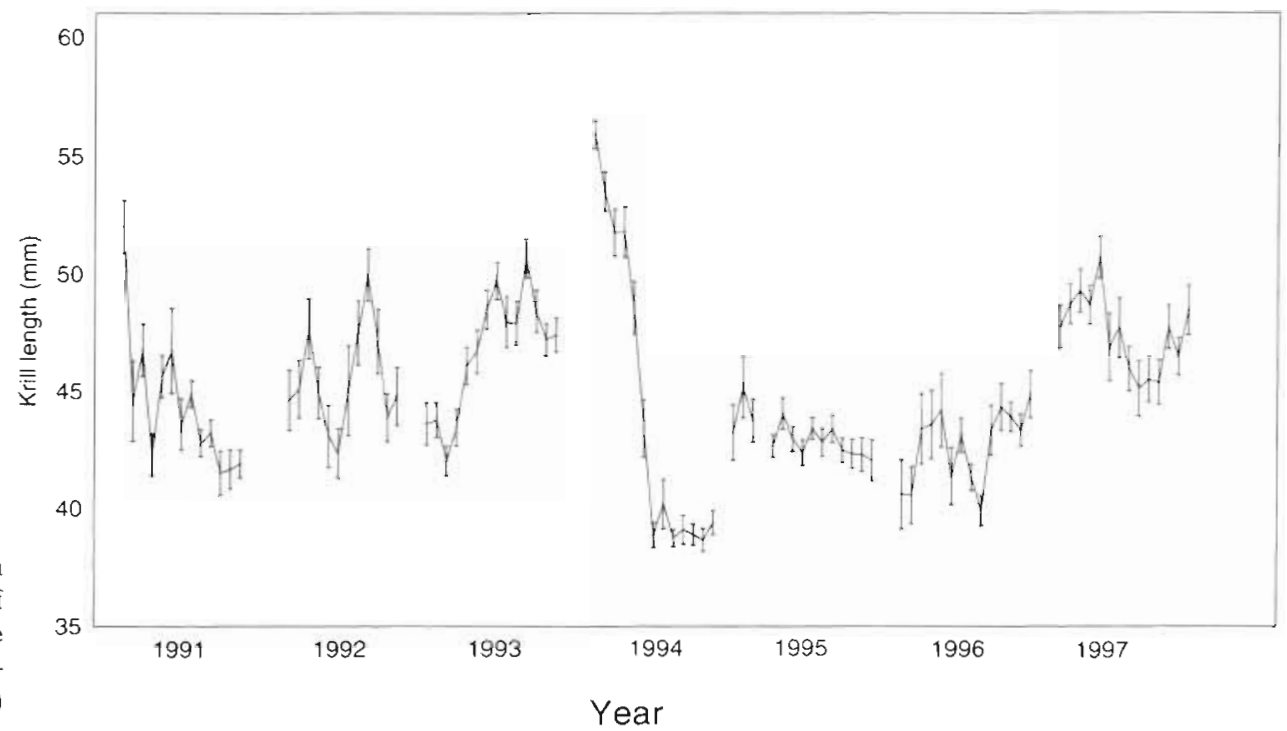

reflected the relative magnitudes of the 2 distinct length modes present during the period. Thus during late December/early January large krill (modal size $58 \mathrm{~mm}$ ) dominated; however, this size class gradually decreased in proportion and had disappeared from the distribution by the end of January (Fig. 3). A second size class (mode 40 to $46 \mathrm{~mm}$ ) appeared during January and by the beginning of February dominated the distribution. During the remainder of 1994 the lengthfrequency distribution had a single mode of $40 \mathrm{~mm}$. In 1991 a similar, but less pronounced, change between modes occurred earlier in the summer (Fig. 6).

When the absolute difference between weekly mean length was calculated using a 3 wk running mean the overall variability between weeks was smallest during the last $3 \mathrm{wk}$ for which data were available (weeks beginning 8 to 23 March). Therefore the mean length of krill taken during this period was compared across years. This showed a consistent pattern of increase from 1991-1993, a marked decrease in 1994 and subsequent consistent increase up to 1997 (Fig. 7).

\section{DISCUSSION}

\section{Comparison of krill caught by predators and nets}

Overall, krill in the diet of predators matched that found in net hauls, especially once known temporal and spatial biases had been accounted for. In each year the major modes in net samples were also represented in predator samples. The modal sizes of krill in predator samples were generally slightly greater than the comparable mode in the net haul samples, which probably reflects the selection by predators of larger krill, which themselves may be under represented in nets.
The differences in the size of krill taken by each species differ from the findings of Reid et al. (1996), where the same 3 predator species all took krill of the same size during February 1986. However, in that year the length-frequency distribution of krill from nets had a single mode at $54 \mathrm{~mm}$ with very few individuals less than $40 \mathrm{~mm}$. This restricted size range, and thus low size diversity of krill, resulted in a high level of overlap between predators. In general, when only large krill were present in net samples all predators took very similar-sized krill; when small krill dominated net samples there were much greater differences in the krill taken by predators. Antarctic fur seals and macaroni penguins are particularly distinct in that when small krill are present they are only taken by macaroni penguins, which often include other small crustaceans in their diet (e.g. the amphipod Themisto gaudichaudii, Croxall et al. 1999, this issue). These differences in the size of krill taken by macaroni penguins and Antarctic fur seals do not appear to be simply a product of their relative body size as both take krill of the same size in some years. Rather they may represent a potential dietary segregation mechanism between 2 species foraging in the same area (Croxall et al. 1997), given their very similar foraging ranges, with little overlap with the exclusively inshore foraging gentoo penguins.

In order to produce the most appropriate comparison with net samples, a composite length-frequency distribution of krill from South Georgia predators should include both Antarctic fur seals and macaroni penguins. Because the differences between predator and net samples are essentially compensatory (i.e. nets underrepresent large krill whereas predators overrepresent large krill), consideration of both such samples should provide the most realistic representation of the structure of the krill population. 


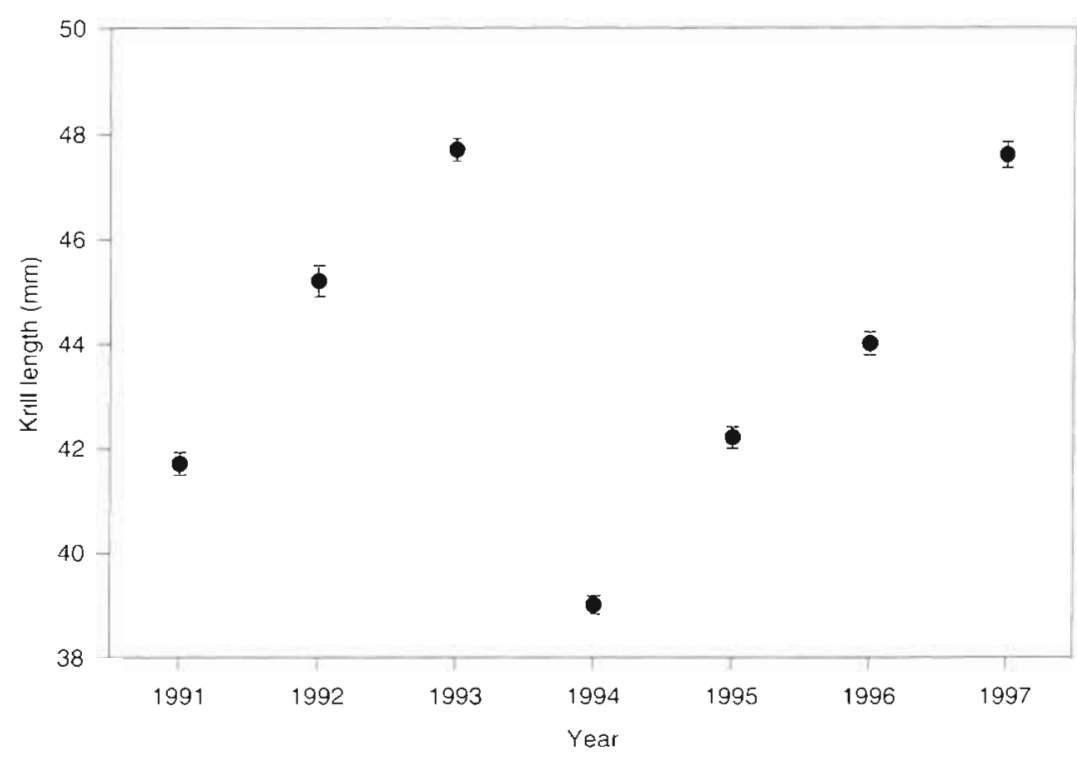

Fig. 7. Mean length of krill in the diet of Antarctic fur seal during the period 8-23 March 1991 to 1997 (error bars show \pm 1 SE)

either nets or predators, with a mean length of approximately $28 \mathrm{~mm}$, are referred to as class 2 . The central mode $(40$ to $44 \mathrm{~mm}$ ), which was the dominant mode in both length-frequency distributions is referred to as class 3. The third size class (mode 52 $\mathrm{mm}$ ) may contain krill from a number of years which are indistinguishable based solely on length and is therefore referred to as class $3+$.

\section{A model of population change}

A population structure will remain stable only if the inflow (immigration and natality) is equal to the outflow (emigration and mortality). In the case of krill at South Georgia, where there is no evidence of a reproductively selfsustaining population (Ward et al.

Ideally such samples should be collected simultaneously and at times when week to week variation is least, i.e. when the population is relatively stable. The present data suggest that this occurs towards the end of the summer (March). For predators, this would only be possible by sampling macaroni penguins on their return to the breeding colonies to moult. However, although the best synoptic picture of krill populations might be obtained by combining samples taken in March from Antarctic fur seals, macaroni penguins and nets, for many purposes a knowledge of the pattern of intra-annual changes in krill length frequency is of great value in interpreting the inter-annual changes. At present the best time series of such data are provided by Antarctic fur seals, which are typically sampled for 12 consecutive weeks, compared with 4 wk for macaroni and gentoo penguins.

\section{Inter-annual variation in krill population dynamics}

The length-frequency distributions of krill from both predators and nets showed 3 fairly consistent modes in their length-frequency distribution which are similar to those found by Mackintosh (1974) in the diet of baleen whales at South Georgia. Assigning age classes to these modes is complicated by the variability in growth rates between years (Rosenberg et al. 1986) and the difficulty of applying growth parameters to a 'model' population (Priddle et al. 1988) that may not necessarily be applicable to the situation at South Georgia. Nevertheless we have followed the model of Priddle et al. (1988) so that the smallest size classes caught by 1990), this would require the effects of emigration and mortality (including predation) to be balanced by immigration (Murphy 1995). In such a situation the length-frequency distribution would be prone to stochastic variation; however, the changes shown in mean krill length (Fig. 8) suggest that systematic, even cyclical, processes are affecting the dynamics of the krill population. Of the potential mechanisms that could produce such a change on the population structure, i.e. emigration, mortality and immigration, we propose a model, based on the length of krill in the diet of Antarctic fur seals, suggesting how changes in the immigration of krill could produce the observed changes in the krill population.

We suggest that changes in the mean length of krill in the March diet of Antarctic fur seals (Fig. 8) reflect the relative proportions of the 3 age classes in the population. Thus in 1991, when mean length was low, we assume that the population contained a large proportion of class 2 krill (although Antarctic fur seals probably only select the largest individuals of this size class), with an almost complete absence of larger krill. By 1992 these class 2 krill have progressed to class 3 and have themselves been replaced by another influx of class 2 krill, resulting in an increase in the mean length of the population. In 1993, when there was no indication of an influx of class $2 \mathrm{krill}$, the population comprised only class 3 and $3+$ krill, producing an even greater mean length. In 1994 only class $3+$ krill (the previous year's class 3) were present during December and early January, whereas the smaller krill present later in the season represented the incoming class 2 . Thus in 1994 there was an absence of class 3 krill, a 

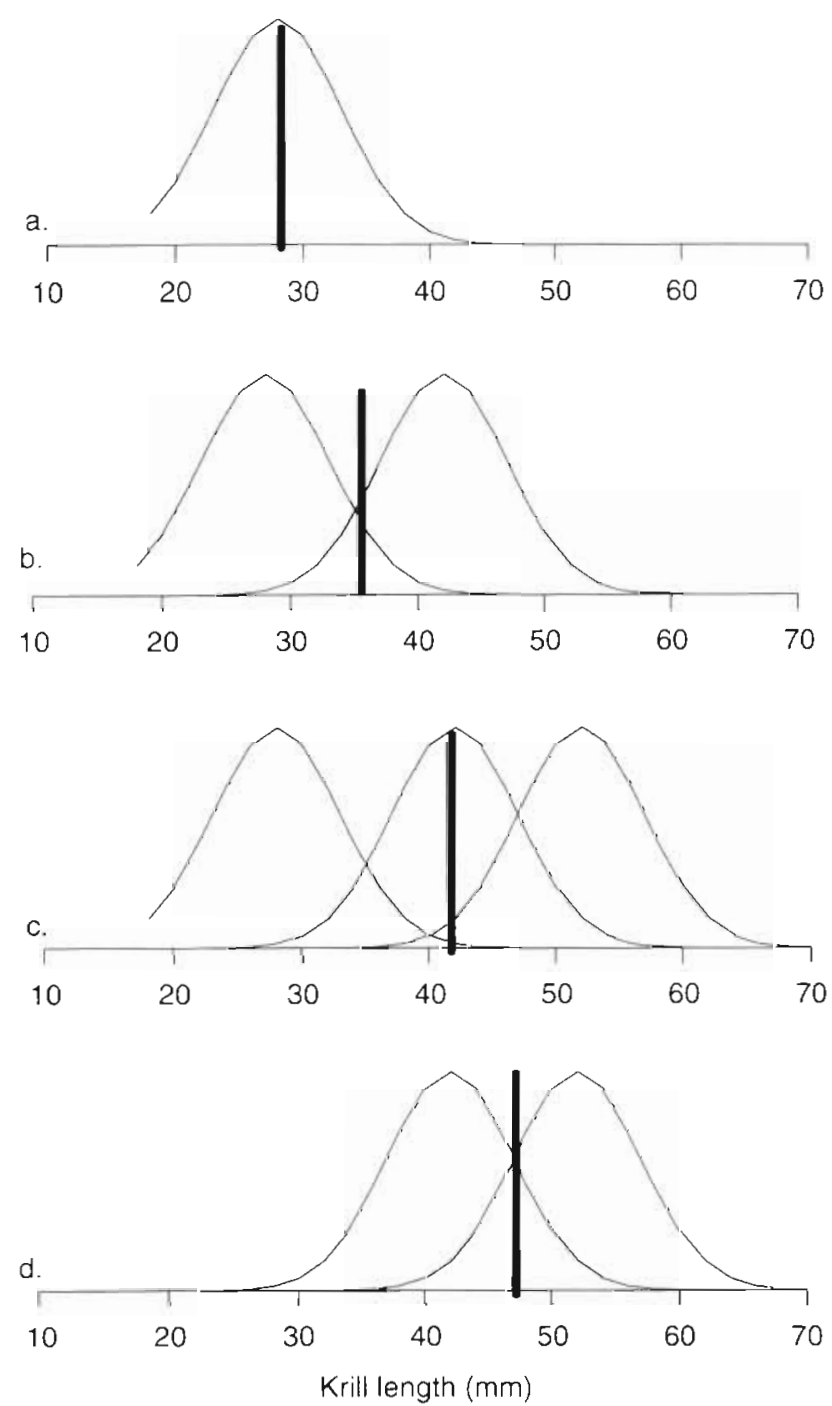

Fig. 8. Schematic diagram showing how the mean size of krill (solid vertical bars) increases in relation to the presence/ absence of a single class of krill. (a) Class 2 only, (b) classes 2 and 3, (c) classes 2,3 and $3+$, (d) classes 3 and $3+$

consequence of the failure of class 2 krill to appear in 1993. This pattern of increasing mean length was repeated during the period from late 1994 (class 2), 1995 (classes 2 and 3), 1996 (classes 2, 3 and $3+$ ) and 1997 (classes 3 and $3+$, absence of class 2); this model of increasing mean length is shown schematically in Fig. 8.

It would appear that class 3 krill, which form the central, dominant mode, are the major component of the biomass of krill at South Georgia. Therefore, in years where they are absent this is reflected not only in reduced overall biomass of krill but also in a predominantly bi-modal distribution of krill whereby the modes reflect the 2 and $3+$ classes, with a gap where the class 3 krill are absent. In order to understand how this situation might occur it is useful to assign age classes to these krill and to examine measures of recruitment from other areas of the Antarctic to investigate potential links in the recruitment and movement of krill.

Some proportion of the krill population at South Georgia is considered likely to originate from the Antarctic Peninsula region (Everson 1976). Thus the failure of particular classes of krill to appear at South Georgia in any year may well be influenced by factors operating in the Peninsula region. Given the potential problems of tracking individual age classes of krill across samples from the Antarctic Peninsula to South Georgia, we focus here on trying to follow the progress of gaps in the population. In particular we can examine whether the absence of an age class in the South Georgia population relates to recruitment and/or spawning stock failure at the Antarctic Peninsula. In the years when the class 2 krill failed to appear at South Georgia, i.e. the years prior to those of krill scarcity (1990 and 1993), the absence of krill of this size range at the Antarctic Peninsula (Siegel \& Loeb 1995) is consistent with this hypothesis. However, there are apparent differences in the assessment of the age of these krill in the 2 locations, which restrict the interpretation of their spawning year (Siegel \& Loeb 1995, Murphy et al. 1998).

In both 1991 and 1994 large krill were replaced by small krill as the dominant mode through the course of the summer. However, these small (incoming class 2) krill appeared to vary in the timing of their appearance from December (1991) to February (1994). A similar shift was recorded by Mackintosh (1974), with large krill forming the dominant mode in October, while by December smaller krill had appeared and formed the dominant mode at $40 \mathrm{~mm}$ from January onwards. The variability in timing of influx of these class 2 krill may be difficult to detect in the diet of predators in years when class 3 krill dominate the population, especially since they are normally underrepresented in the diet of predators. During periods of low biomass, caused by an absence of class 3 krill, the timing and magnitude of the incoming class 2 krill may be a key determinant of the duration and severity of the period of krill scarcity. Therefore, not only is there a potential effect of reduced krill biomass through recruitment failure but the timing and magnitude of the incoming year class may also be a crucial factor.

Some component of the krill population at South Georgia may originate in the Weddell Sea (Everson 1976), an area for which we have no recruitment indices. Therefore it is possible that a separate suite of factors, originating in a different area of the Antarctic and affecting a separate population of krill, may also influence the pattern of inter-annual variability at South Georgia. However, the simultaneous absence of 
the same component of the krill population in different areas does indicate the large scale variability acting across the Scotia Sea. This supports suggestions that periodic variability in the krill population at South Georgia is linked to a range of large-scale physical process such as sea ice extent and duration (Siegel \& Loeb 1995, Murphy et al. 1998).

\section{Summary}

There were small differences in the length-frequency distributions of krill from predators and nets that were attributable to some combination of differences in spatio/temporal aspects of sampling and predator/net selectivities. When these biases were accounted for, the 2 data sets reflected broadly the same population structure on most sampling occasions. When the time series of data from predators is used to examine krill population processes at South Georgia there are characteristic changes in the krill population structure consistent with a model of recruitment failure in the year preceding a period of low krill biomass. This clearly demonstrates the crucial role of data from krill-dependent predators in describing the nature of the observed variability and represents an important advance in our understanding of the local krill population dynamics. The apparent absence of the same size component of the krill populations in the Antarctic Peninsula region and South Georgia indicates the potential for large-scale interpretations and implications of these data; however, the complex nature of krill flux in the Southern Ocean makes a unitary explanation of population changes at South Georgia unlikely.

Acknowledgements. We thank Tony Walker, Nic Huin, Richard Humpidge and Robbie Taylor for help with collection and measurement of krill from predators at Bird Island.

\section{LITERATURE CITED}

Boyd IL, Arnould JPY, Barton T, Croxall, JP (1994) Foraging behaviour of Antarctic lur seals during periods of contrasting prey abundance. J Anim Ecol 63:703-713

Brierley AS, Watkins JL, Murray AWA (1997) Interannual variability in krill abundance at South Georgia. Mar Ecol Prog Ser 150:87-98

Croxall JP, Pilcher MN (1984) Characteristics of krill Euphausia superba eaten by Antarctic fur seals Arctocephalus gazella at South Georgia. Br Antarct Surv Bull 63:117-125

Croxall JP, McCann TS, Prince PA, Rothery P (1988) Reproductive performance of seabirds and seals at South Georgia and Signy Island, South Orkney Islands, 1976-1987: implications for Southern Ocean monitoring studies. In Sahrhage, D (ed) Antarctic Ocean and resources variability. Springer-Verlag, Berlin, p 261-285
Croxall JP, Prince PA, Reid K (1997) Dietary segregation of krill-eating South Georgia seabirds. J Zool, Lond 242: $531-556$

Croxall JP, Reid K, Prince PA (1999) Diet, provisioning and productivity responses of marine predators to differences in availability of Antarctic krill. Mar Ecol Prog Ser 177: $115-131$

Everson I (1976) Antarctic krill: a reappraisal of its distribution. Polar Rec 8:15-23

Everson I, Bone DG (1986) Effectiveness of the RMT8 system for sampling krill Euphausia superba swarms. Polar Biol 6: $83-90$

Hill HJ (1990) A new method for the measurement of Antarctic krill Euphausia superba Dana from predator food samples. Polar Biol 10:317-320

Hill HJ, Trathan PN, Croxall JP, Watkins JL (1996) A comparison of Antarctic krill Euphausia superba caught in nets and taken by macaroni penguins Eudyptes chrysolophus: evidence for selection? Mar Ecol Prog Ser 140:1-11

Hovekamp S (1989) Avoidance of nets by Euphausia pacifica in Dabob Bay. J Plankton Res 11:907-924

Kock KH, Wilhelms S, Everson I, Groger J (1994) Variation in the diet composition and feeding intensity of mackerel icefish Champsocephalus gunnari at South Georgia (Antarctic). Mar Ecol Prog Ser 108:43-57

Lockyer C (1973) Wet weight, volume and length correlation in the Antarctic krill Euphausia superba. Discovery Rep 36:152-155

Mackintosh NA (1974) Sizes of krill eaten by whales in Antarctica. Discovery Rep 36:157-178

Marr J (1962) The natural history and geography of the Antarctic krill Euphausia superba Dana. Discovery Rep $32: 33-464$

Miller DGM, Hampton I (1989) Biology and ecology of the Antarctic krill Euphausia superba Dana: a review. Scientific Committee on Antarctic Research, Cambridge

Murphy EJ (1995) Spatial structure of the Southern Ocean ecosystern: predator-prey linkages in Southern Ocean food webs. J Anim Ecol 64:333-347

Murphy EJ, Watkins JL, Reid $K$, Trathan PN, Everson I, Croxall JP, Priddle J, Brandon MA, Brierley A, Hofman E (1998). Interannual variability of the South Georgia marine ecosystem: biological and physical sources of variation in the abundance of krill. Fish Oceanogr 7:381-390

Priddle J, Croxall JP, Everson I, Heywood RB, Murphy EJ, Prince PA, Sear CB (1988) Large-scale fluctuations in distribution and abundance of krill-a discussion of possible causes. In: Sahrhage, D (ed) Antarctic Ocean and resources variability. Springer-Verlag, Berlin, p 169-182

Reid K, Arnould JPY (1996) The diet of Antarctic fur seals Arctocephalus gazella during the breeding season at South Georgia. Polar Biol. 16:105-114

Reid K, Trathan PN, Croxall JP, Hill HJ (1996) Krill caught by predators and nets: differences between species and techniques. Mar Ecol Prog Ser 140:13-20

Rosenberg AA, Beddington JR, Basson M (1986) Growth and longevity of krill during the first decade of pelagic whaling. Nature 324:152-154

Shannon CE, Weaver W (1949) The mathematical theory of communication. University of Illinois Press, Urbana

Siegel V, Loeb V (1995) Recruitment of Antarctic krill Euphausia superba and possible causes for its variability. Mar Ecol Prog Ser 123:45-56

Ward P, Atkinson A, Peck JM, Wood AG (1990) Euphausid life cycles and distribution around South Georgia. Antarct Sci $2: 43-52$

Submitted: May 19, 1998; Accepted: September 24, 1998

Proofs received from author(s): January 29, 1999 